\title{
Relationship between acoustic aperture size and tumor conditions for external ultrasound hyperthermia
}

\author{
Win-Li Lin \\ Institute of Biomedical Engineering, National Taiwan University, Taipei, Taiwan \\ Jia-Yush Yen \\ Department of Mechanical Engineering, National Taiwan University, Taipei, Taiwan \\ Yung-Yaw Chen \\ Department of Electrical Engineering, National Taiwan University, Taipei, Taiwan \\ Kuo-Wen Jin \\ Department of Mechanical Engineering, National Taiwan University, Taipei, Taiwan \\ Ming-Jium Shieh ${ }^{\text {a) }}$ \\ Institute of Biomedical Engineering, National Taiwan University, Taipei, Taiwan
}

(Received 14 April 1998; accepted for publication 25 February 1999)

\begin{abstract}
External ultrasound hyperthermia is a very flexible modality for heating deep-seated tumors due to its deep penetration and focusing ability. However, under the constraints of the available acoustic aperture size for the ultrasonic beam, ultrasonic attenuation, as well as other anatomic properties, it may not be able to deliver sufficient ultrasonic energy to heat a large tumor located in a deep region without overheating the normal tissue between the tumor and the aperture. In this work, we employ a simulation program based on the steady-state bioheat transfer equation and an ideal ultrasound power deposition (a cone with convergent/divergent shape) to examine the relationship between the minimal diameter of the acoustic aperture and the tumor conditions. Tissue temperatures are used to determine the appropriate aperture diameter and the input power level for a given set of tumor conditions. Due to the assumed central axis symmetry of the power intensity deposition and anatomic properties, a two-dimensional $(r-z)$ simulation program is utilized. Factors determining the acoustic aperture diameter and the input power level considered here are the tumor size, tumor depth, ultrasonic attenuation in tissue, blood perfusion, and temperature of the surface cooling water. Simulation results demonstrate that tumor size, tumor depth, and ultrasonic attenuation are major factors affecting the aperture diameter of the ultrasonic beam to obtain an appropriate temperature distribution, while blood perfusion and the temperature of the surface cooling water are the minor factors. Plots of the effects of these factors can be used as the guideline for designing an optimal ultrasound heating system, arranging the transducers, and planning further treatments. (C) 1999 American Association of Physicists in Medicine. [S0094-2405(99)01505-9]
\end{abstract}

Key words: external ultrasound hyperthermia, acoustic aperture, tumor conditions, temperature distributions

\section{INTRODUCTION}

Due to the physical characteristics of acoustic propagation in living tissues, the power deposition field of ultrasound energy can be focused to specific depths in soft tissues. To treat deep-seated tumors, focused or multiple overlapping fields must be used. Three general approaches are evaluated in the laboratory and/or in clinical trials: (a) single or multiple beams directed or focused onto the tumors, ${ }^{1-5}$ (b) a wellfocused beam scanned rapidly across the tumor to generate an enhanced temperature distribution, ${ }^{6-11}$ and (c) a phased array excited by independent sources with defined phases and amplitudes. ${ }^{12-14}$ The above approaches attempt to select the driving frequency, arrange the system parameters, and use surface cooling water to reduce the skin temperature in order to obtain an appropriate power deposition to heat a deep-seated tumor. The ultrasonic beam must enter through a large skin area and then converge into a much smaller target area in order to induce a higher temperature at the desired depth. ${ }^{15}$ Therefore, the above systems would overheat the intervening normal tissue between the aperture and the target volume during the treatments when the acoustic aperture size is insufficient for a specific tumor. The geometrical gain $\left(D^{2} / d^{2}\right.$, as shown in Fig. 1) needed to overcome the attenuation losses can be calculated. Based on the equal absorbed power density at the skin surface and at the depth to be heated, Hynynen ${ }^{15}$ plotted the minimal diameter of the acoustic aperture required. According to his results, the required geometrical gain depends heavily on the driving frequency, as well as the diameter and depth of the target volume.

In this study, we investigate the minimal diameter of an aperture required for an ultrasonic beam to heat a deepseated tumor based on the bioheat transfer equation to determine the temperature distributions when the tumor condi- 


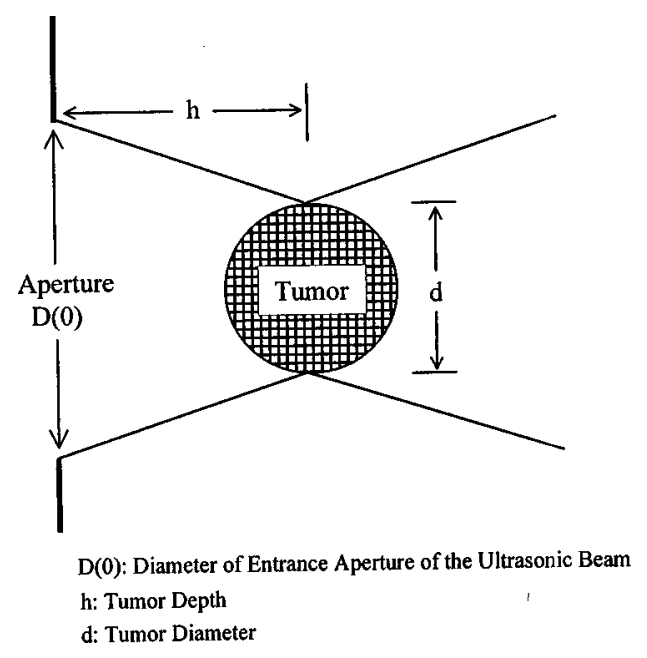

FIG. 1. Diagram of the geometry studied for the ultrasonic aperture. The entrance aperture $[D(0)]$ of the ultrasonic beam is at the left. The narrowest region is the focal zone and a spherical tumor with a diameter of $d \mathrm{~cm}$ is assumed to be centered at this focal region. The temperatures at tumor's front and side boundary are set to $43^{\circ} \mathrm{C}$ during the acoustic aperture search process.

tions are given. A comprehensive investigation reveals that the aperture diameter is proportional to the tumor depth, the tumor diameter, and the ultrasonic attenuation in tissue. The temperature of the surface cooling water can be used to effectively reduce the tissue temperature close to the skin, but cannot reduce the acoustic aperture diameter required for appropriately heating a deep-seated tumor. A higher blood perfusion produces a higher maximal temperature within the tumor region; however, it is only a minor factor affecting the acoustic aperture size.

\section{METHOD}

The region of significant ultrasound intensity within the tissue can be modeled as two truncated cones yielding a convergent/divergent shape as shown in Fig. 1. The left side with a diameter of $D \mathrm{~cm}$ is referred to as the entrance aperture for the ultrasonic beam. The narrowest region, with a diameter of $d \mathrm{~cm}$, is regarded as the focal zone, while beyond this zone the ultrasonic beam diverges. A spherical tumor with a diameter of $d \mathrm{~cm}$ is assumed to be centered at the focal region. This type of power deposition can form an appropriate temperature distribution for deep-seated tumor heating, provided the entrance aperture diameter is sufficiently large to overcome the ultrasonic attenuation caused by the tissue. This deposition also can avoid overheating the region beyond the tumors because of the attenuation and the divergence of ultrasonic beam. A scanned, focused ultrasound heating system ${ }^{11,16}$ can yield a power deposition close to this ideal convergent/divergent shape by varying the scan parameters (tilt angle, rotation angle, scan radius, focal depth, and input power level). To obtain a relatively simple but realistic approximation and avoid overly complicated calculations, the deposition of ultrasonic intensity within the conical region was simplified as a uniform distribution at each depth. Moreover, the power at each depth was assumed to be equally attenuated, ${ }^{16,17}$

$$
\begin{aligned}
& Q(z)=Q(0) e^{-2 \mu z}, \\
& I(z)=Q(z) / A(z),
\end{aligned}
$$

and

$$
q(z)=2 \mu I(z),
$$

in which $Q(0)$ is the total power propagating through the acoustic aperture, $Q(z)$ is the total power propagating through the area at depth $z \mathrm{~cm}, A(z)$ is the cross-section area of the conical power region at depth $z \mathrm{~cm}, \mu$ is ultrasound attenuation, $I(z)$ is the power intensity at depth $z \mathrm{~cm}$, and $q(z)$ is the absorbed power density at depth $z \mathrm{~cm}$.

To solve for the temperature distribution, Pennes, 18 steady-state bioheat transfer equation (BHTE) was used, i.e.,

$$
-k \nabla^{2} T+W c_{b}\left(T-T_{a r}\right)=q .
$$

The above BHTE is a simplification which neglects the effects of discrete blood vessels, the redistribution of thermal energy within the local vascular network, and metabolic heat production. However, the BHTE is a good approximation which offers a practical approach for modeling biothermal processes $^{19-21}$ and performing general parameter studies. For convenience, this bioheat transfer equation can also be written in other forms ${ }^{22,23}$ to have a better description of the heat transfer in the tissue. We select the thermal properties to approximate averages for soft tissues. ${ }^{24-26}$ The thermal conductivity $(k)$ is $0.5\left(\mathrm{Wm}^{-1}{ }^{\circ} \mathrm{C}^{-1}\right)$, the specific heat of blood $\left(c_{b}\right)$ is $3770\left(\mathrm{Jkg}_{g}{ }^{-1}{ }^{\circ} \mathrm{C}^{-1}\right)$, and the arterial temperature $\left(T_{a r}\right)$ is $37^{\circ} \mathrm{C}$. The absorbed ultrasonic power density $(q)$ was obtained using the above procedure for a given total input power $Q(0)$. All attenuated ultrasonic energy was assumed to be absorbed by the tissue in the heating region. The anatomic properties (except blood perfusion) were assumed to remain constant throughout the entire field, and metabolism was neglected due to its small contribution to the temperature changes. ${ }^{20,27}$ Blood perfusion distributions used were symmetrical about the central axis $(z)$, and thus all cases had a symmetrical, two-dimensional field $(r, z)$. The diameter and the thickness of the cylindrical volume of the simulated tissue were automatically changed, their sizes depending on the aperture diameter and the tumor depth/size. When the dimension of the aperture diameter is close to the simulated tissues diameter, the radius of simulated tissue is automatically expanded to avoid the effect of the boundary condition. The front surface boundary condition was a constant value which was equal to the temperature of the surface cooling water; the other surfaces were a constant temperature $37^{\circ} \mathrm{C}$. The central axis was treated as adiabatic ${ }^{16}$ because no energy transfer occurs in the radial direction at the center line due to the symmetry of both the power distribution and the anatomical and physiological properties. The steady-state BHTE was numerically approximated using the successive-overrelaxation technique and the method of central finite differences ${ }^{28}$ to obtain the two-dimensional temperature field 


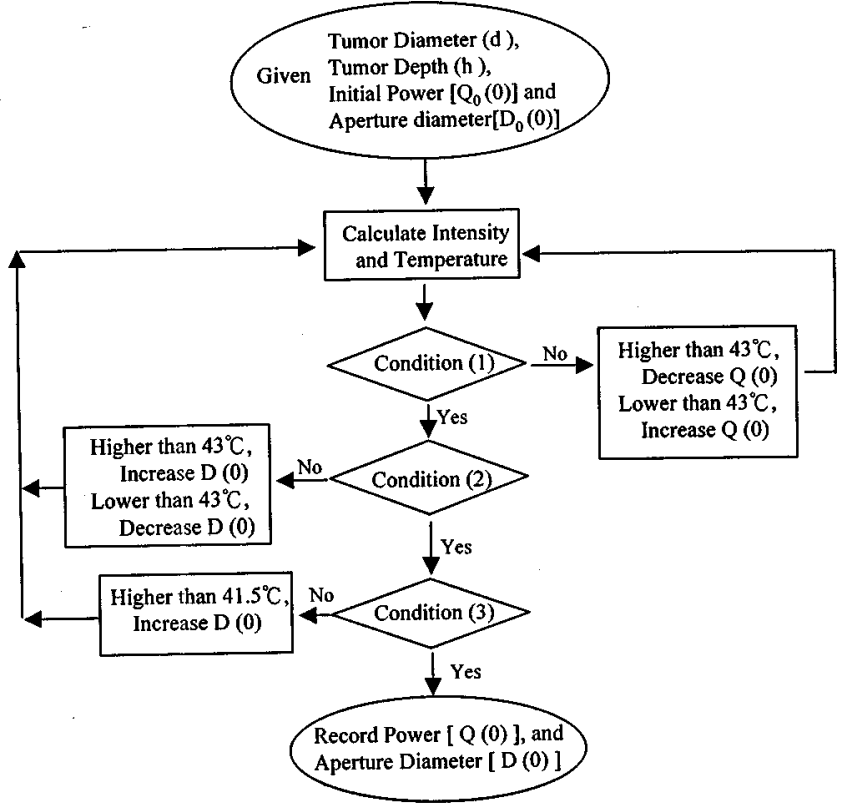

Condition (1): Temperature at Tumor's Side Boundary $=43 \pm 0.1^{\circ} \mathrm{C}$ Condition (2): Temperature at Tumor's Front Boundary $=43 \pm 0.1^{\circ} \mathrm{C}$ Condition (3): Temperature at the Location $1 / 2$ Diameter away from the Tumor's Front Boundary $\leq 41.5 \pm 0.1^{\circ} \mathrm{C}$

FIG. 2. Flow chart of the search algorithm used to determine the minimal diameter of the acoustic aperture and the input power level for a given set of tumor conditions. The temperature conditions (1-3) are employed as the constraint criteria to obtain an appropriate temperature distribution for the treatment. $D_{0}(0)$ and $Q_{0}(0)$ are the initial guess values of the aperture diameter $[D(0)]$ and the total input power $[Q(0)]$ propagating through the acoustic aperture, respectively.

$(r-z)$ induced by the power deposition for a given set of tumor conditions, acoustic aperture size, and input power level. The grid spacing used is $0.2 \mathrm{~cm}$, the over-relaxation factor is 1.8 , and the convergence criterion is the root mean square error less than $10^{-7}$. The depth of focal zone is $5-15$ $\mathrm{cm}$, the diameter of focal zone is $3-7 \mathrm{~cm}$, the ultrasonic attenuation is $5-15 \mathrm{~Np} / \mathrm{m}$, the blood perfusion is $1-15 k_{g} \mathrm{~m}^{-3} \mathrm{~s}^{-1}$, and the temperature of the surface cooling water is $20^{\circ} \mathrm{C}-37^{\circ} \mathrm{C}$.

\section{RESULTS AND DISCUSSION}

The procedure shown in Fig. 2 is used to search for the minimal diameter of the acoustic aperture and input power level which will result in a temperature distribution which meet temperature conditions 1 to 3 for each set of tumor conditions. During the search process, temperature constraints are employed as the determination conditions for the search process. The temperatures at the edges of the focal zone and at the tumors front boundary are set to reach $43{ }^{\circ} \mathrm{C}$. In addition, the regions temperature for $\frac{1}{2} d \mathrm{~cm}$ distance from the tumor's front boundary is set $\leqslant 41.5^{\circ} \mathrm{C}$. Those temperature conditions are used to obtain a minimal power level and a minimal acoustical aperture size which can raise the tumor temperature to $43^{\circ} \mathrm{C}$ without overheating the normal tissue, particularly the region close to the skin.
Figure 3(a) shows the diameters of the acoustic aperture required for the tumors located at different depths based on the above temperature criterion and on the equal intensity criterion (to produce an equal power intensity at the skin and at tumor depth ${ }^{15}$ ). This figure reveals that (a) the aperture diameter for each criterion increases with the tumor depth, and (b) the aperture diameter for the temperature criterion is larger than that for the equal intensity criterion. A larger aperture will reduce the temperature close to the skin and produce a better temperature distribution for the treatment. Figures 3(b) and 3(c) present the temperature distributions based on the temperature and the equal intensity criteria assuming a $5 \mathrm{~cm}$ tumor is located at $13 \mathrm{~cm}$ depth. Clearly, an overheating region close to the skin occurs for the equal intensity criterion. This finding suggests that the equal intensity criterion can be used to reach the treatment temperature within the tumor region, but cannot avoid overheating the normal tissue.

In addition to the tumor depth, other factors that may influence the diameter of acoustic aperture and the input power level are tumor size, ultrasonic attenuation of tissue, blood perfusion, and temperature of the surface cooling water. Figure 4 indicates the effects of tumor size on the aperture diameter, using tumor diameters of 3,5 , and $7 \mathrm{~cm}$. Figure 5 shows the simulation results for the effects of ultrasonic attenuation of tissue on the acoustic aperture diameter. According to those results, the aperture diameter dramatically changes according to the attenuation for given tumor conditions. In order to be able to heat a deep-seated tumor, a higher attenuation requires a significantly larger acoustic aperture to compensate for the energy decay. As an example, the aperture diameter is 15,19 , and $27 \mathrm{~cm}$ for a 5 $\mathrm{cm}$ tumor located at $9 \mathrm{~cm}$ depth with attenuation 5, 10, and $15 \mathrm{~Np} / \mathrm{m}$, respectively. However, the aperture diameter is larger than $35 \mathrm{~cm}$ for a $5 \mathrm{~cm}$ tumor located at a depth of 11 , 17 , and $29 \mathrm{~cm}$, as the attenuation is 15,10 , and $5 \mathrm{~Np} / \mathrm{m}$, respectively. Here ultrasonic attenuation in tissue changes as a function of driving frequency and tissue properties. For most tissue this change can be approximated as being directly proportional to driving frequency. This finding demonstrates that a lower frequency transducer should be employed to heat a large and deep-seated tumor if the acoustic aperture is limited.

Blood perfusion is a critical factor affecting the temperature distribution. A higher blood perfusion requires a higher input power to reach the treatment temperature. This implies that a larger acoustic aperture might be necessary for a deepseated tumor with a higher blood perfusion. Blood perfusion varies between different tissue types and with position within an organ as the tissue function and composition change. Typical blood perfusion rates are 1-11.5, 0.15-0.5, 0.5, 0.1, 9 , and $9.5 k_{g} \mathrm{~m}^{-3} \mathrm{~s}^{-1}$ for skin, fat, muscle, bone, brain and liver, respectively. ${ }^{29}$ The reported perfusions of human tumors are $0.15-16 k_{g} \mathrm{~m}^{-3} \mathrm{~s}^{-1}$, with a median value $2.9 k_{g} \mathrm{~m}^{-3} \mathrm{~s}^{-1} .{ }^{30}$ To investigate the influence of blood perfusion on the acoustic aperture, a uniform perfusion is initially assumed for the entire region (both tumor and normal tissues) and the perfusion rate $[W$ in Eq. (4)] is varied from 1.0 

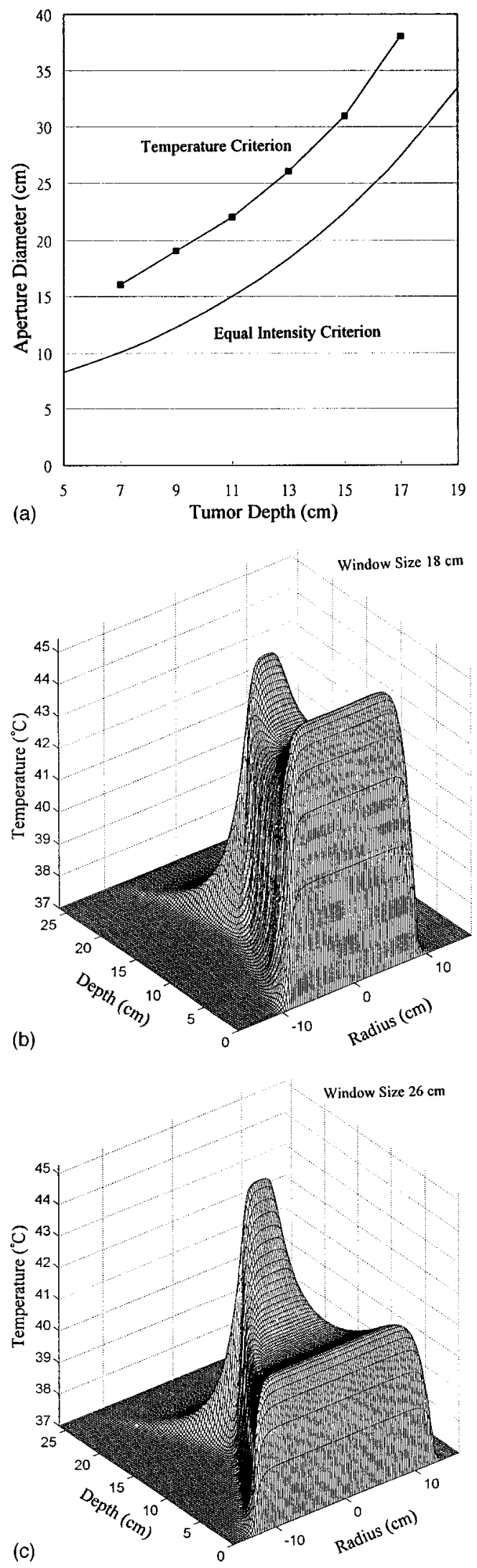

FIG. 3. (a) The acoustic apertures required at different tumor depths for the temperature and the equal intensity criteria; (b) temperature distribution for the equal intensity criterion; (c) temperature distribution for the temperature criterion. For (a)-(c) the tumor diameter is $5 \mathrm{~cm}$, tumor depth is $13 \mathrm{~cm}$, blood perfusion is $5 \mathrm{~kg} \mathrm{~m}^{-3} \mathrm{~s}^{-1}$, and ultrasonic attenuation in tissue is 10 $\mathrm{Np} / \mathrm{m}$.

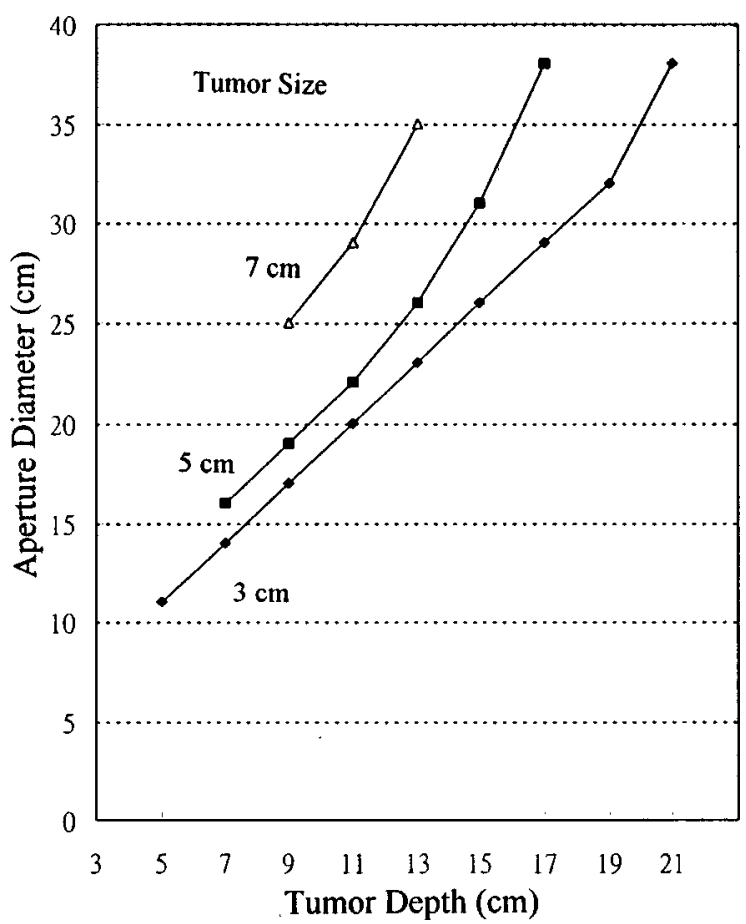

FIG. 4. The diameter of acoustic aperture required to produce an appropriate temperature distribution for three different diameters of the target volume located at different depths. The perfusion is $5 k_{g} \mathrm{~m}^{-3} \mathrm{~s}^{-1}$ and the attenuation is $10 \mathrm{~Np} / \mathrm{m}$.

to $15.0 k_{g} \mathrm{~m}^{-3} \mathrm{~s}^{-1}$. Figure 6 (a) summarizes these results, demonstrating that the perfusion has only a slight effect on the acoustic aperture. To study the effect of nonuniform blood perfusion on the acoustic aperture size, the normal tissue perfusion was held constant at a value of either 1.0 or $10.0 k_{g} \mathrm{~m}^{-3} \mathrm{~s}^{-1}$, while the tumor perfusion was set at either 0.5 or $2.0 k_{g} \mathrm{~m}^{-3} \mathrm{~s}^{-1}$. Figure 6(b) shows the simulation results, indicating the effect of perfusion levels on the acoustic aperture size. This figure indicates that the aperture size is very closely dependent on the relative magnitude of blood perfusion levels between normal tissue and tumor. The sequence of acoustic aperture diameter $(\mathrm{cm})$ from large to small for the sets of normal tissue and tumor perfusions is (1, $2),(5,5),(1,0.5),(10,2)$, and then $(10,0.5)$ (unit: $\left.k_{g} \mathrm{~m}^{-3} \mathrm{~s}^{-1}\right)$. It requires a larger aperture size for the case where the tumor's perfusion is higher than normal tissues. As the relative magnitude of blood perfusion between the tumor and normal tissue becomes smaller, the aperture size required decreases.

The temperature of surface cooling water can reduce the heated temperature in the region close to the skin to about $1.0 \mathrm{~cm}$ in depth when an external ultrasound heating system is used. When a planar transducer is employed to heat a superficial tumor, the temperature of the surface cooling water can be regarded as an input parameter to vary the maximal temperature depth within a few centimeters. To heat a deep-seated tumor, the cooling water can be used to reduce the skin surface temperature. However, further study is required to investigate the effect of the cooling water temperature on the acoustic aperture diameter. Figure 7(a) presents 


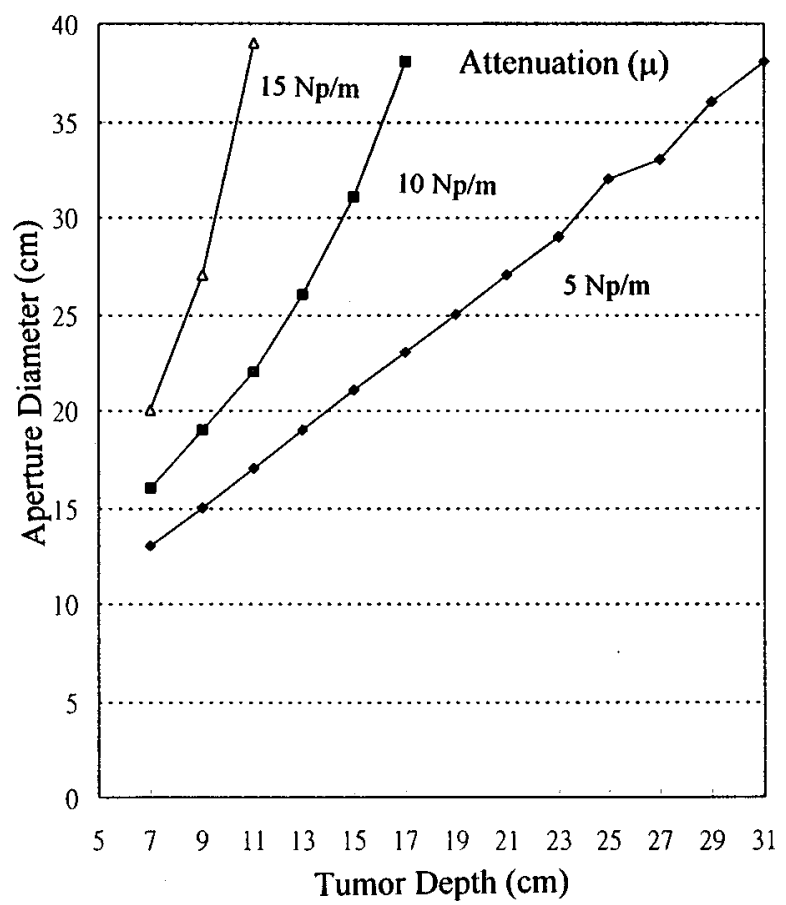

FIG. 5. The diameter of acoustic aperture required for compensating the ultrasonic attenuation in soft tissues as a function of depth for various attenuation values. The tumor diameter is $5 \mathrm{~cm}$ and blood perfusion is $5 k_{g} \mathrm{~m}^{-3} \mathrm{~s}^{-1}$.

the simulation results, demonstrating the relationship between the cooling water temperature and the acoustic aperture size. This figure indicates that the cooling water temperature only slightly influences the size of the acoustic aperture required. This finding seems to be contradictory to the conventional concept that a lower temperature of the surface cooling water can solve the overheating problem and to reduce the aperture diameter. Figure 7(b) indicates the temperature distribution along the central axis for cooling water temperatures $20^{\circ} \mathrm{C}$ and $37^{\circ} \mathrm{C}$. This figure clearly illustrates that the effect of cooling water on the temperature distribution is limited to approximately $2.0 \mathrm{~cm}$ depth, having only a slight effect at deeper levels. This finding suggests that the cooling water can change the temperature distribution close to the skin, but cannot effectively reduce the overheating problem in deeper tissues or decrease the acoustic aperture diameter.

\section{CONCLUSION}

The above study indicates that tumor diameter, tumor depth, ultrasonic attenuation, and driving frequency are the major factors determining the minimal diameter of the acoustic aperture which is required to produce an appropriate temperature for deep-seated tumor heating. Larger, deeper tumors with a higher driving frequency transducer would require a significantly larger acoustic aperture to heat the tumor without overheating the normal tissue close to the skin. Blood perfusion only slightly influences the aperture size when a constant, uniform perfusion is used for both tumor and normal tissue. However, when the tumor perfu-

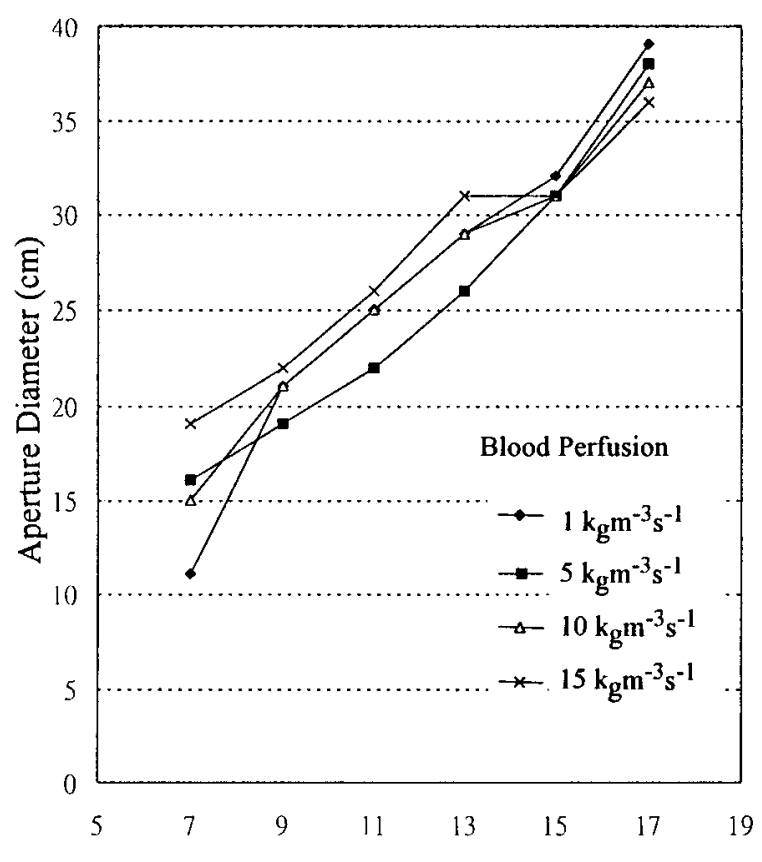

(a) Tumor Depth $(\mathrm{cm})$

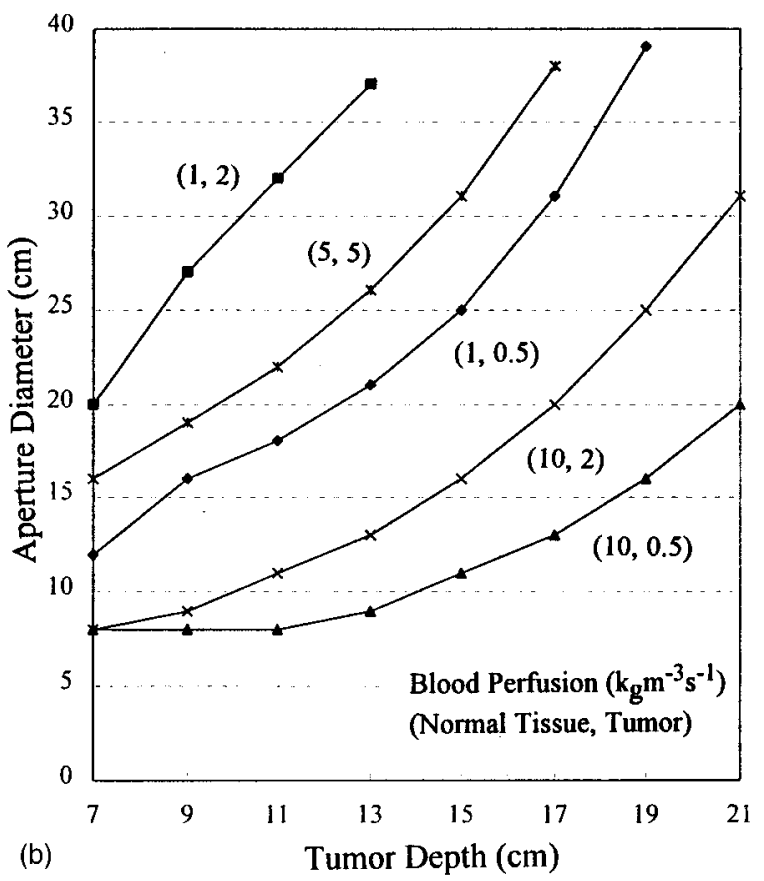

FIG. 6. The diameter of acoustic aperture required to produce an appropriate temperature distribution for different perfusions of the simulated volume. The tumor diameter is $5 \mathrm{~cm}$ and the ultrasonic attenuation is $10 \mathrm{~Np} / \mathrm{m}$. (a) A uniform perfusion is assumed for the entire simulated volume; (b) the perfusions $\left(k_{g} \mathrm{~m}^{-3} \mathrm{~s}^{-1}\right)$ for the normal tissue and for the tumor region are shown in the first and the second place of the quotation mark.

sion is lower than that of normal tissue, a smaller acoustic aperture is deemed necessary; for the reverse condition, a larger acoustic aperture is required. The temperature of the surface cooling water only slightly influences the acoustic aperture size. A lower temperature of cooling water can reduce the tissue temperature close to the skin, but has a limited effect on the temperature distribution for deeper tissue 

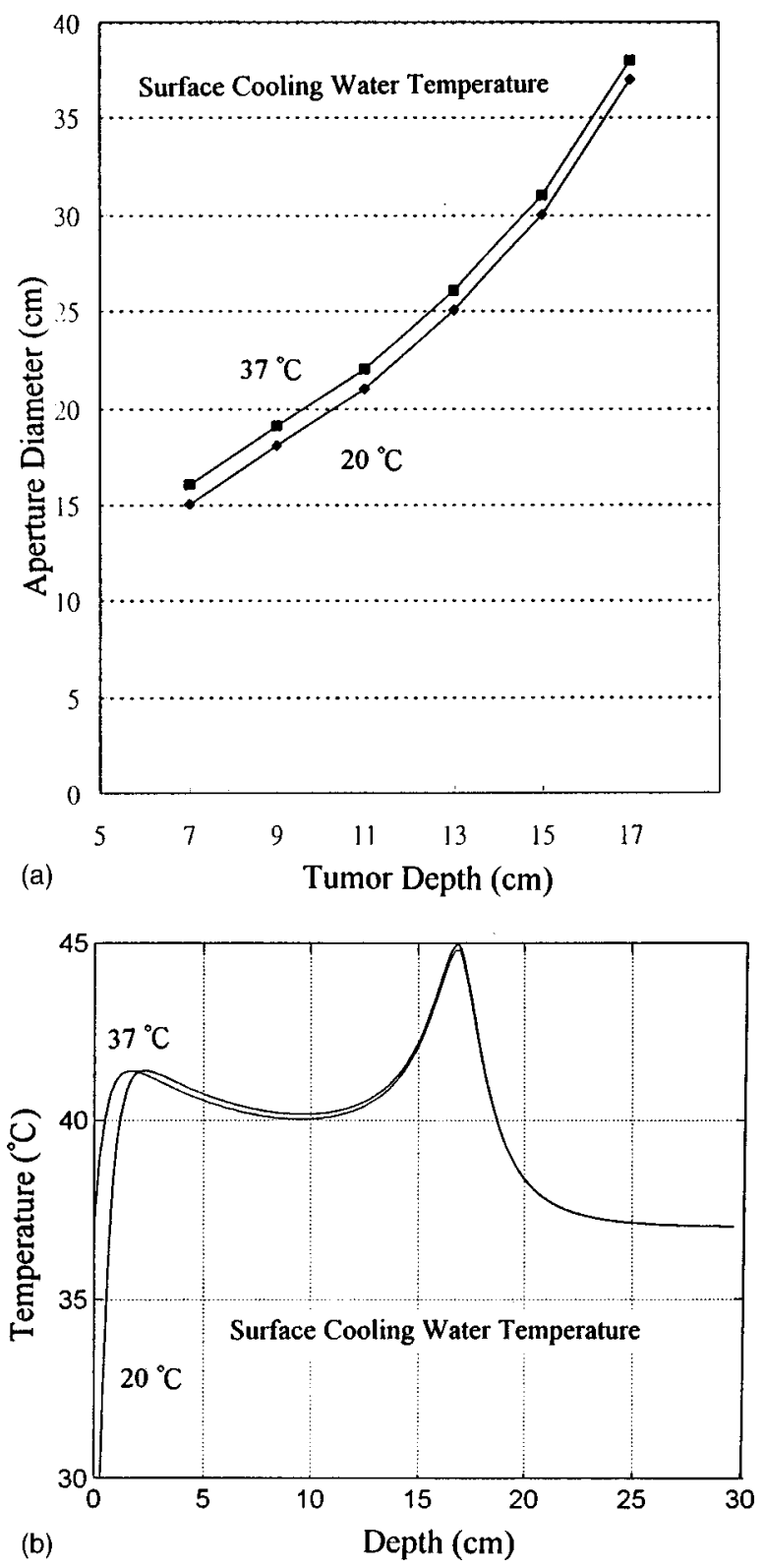

FIG. 7. The effects of surface cooling water temperature on the diameter of acoustic aperture required to produce a suitable temperature distribution. The tumor diameter is $5 \mathrm{~cm}$ and the ultrasonic attenuation is $10 \mathrm{~Np} / \mathrm{m}$. (a) Plot of the relationship between the acoustic aperture size and the surface cooling water temperature, for two temperatures $37^{\circ} \mathrm{C}$ and $20^{\circ} \mathrm{C}$; (b) temperature distribution along the central axis for these two cases.

and consequently on the acoustic aperture diameter. The simulations indicate that with knowledge of tumor size, tumor depth, and tissue properties, an appropriate acoustic aperture size and driving frequency can be determined. Through proper treatment planning, a heating system based on a given acoustic aperture can be arranged to form an appropriate ultrasonic power deposition which can best treat the intended tumor volume while avoiding overheating normal tissue.

\section{ACKNOWLEDGMENTS}

The authors would like to thank the National Science Council and the Department of Health of the Republic of
China for partial support of this research under Contract Nos. NSC 87-2213-E-002-075 and DOH 87-HR-635, respectively.

${ }^{a)}$ Corresponding author: Institute of Biomedical Engineering, College of Medicine, National Taiwan University, No. 1, Sec. 1, Jen-Ai Road, Taipei, Taiwan.

${ }^{1}$ P. Fessenden, E. R. Lee, T. L. Anderson, J. W. Strohbehm, J. L. Meyer, T. V. Samulski, and J. R. Marmor, "Experience with a multitransducer ultrasound system for localized hyperthermia of deep tissues,' IEEE Trans. Biomed. Eng. 31, 126-135 (1984).

${ }^{2}$ E. Seppi, E. Shapiro, L. Zitelli, S. Henderson, A. Wehlau, G. Wu, and C. Dittmer, "A large aperture ultrasonic array system for hyperthermia treatment of deep-seated tumors," in Proceedings of the IEEE Ultrasonic Symp. (1985), pp. 942-949.

${ }^{3}$ K. Hynynen, D. J. Watmough, M. Shammari, G. Wilmot, M. S. N. Murthy, J. R. Mallard, M. Fuller, and T. Sarkar, "A clinical hyperthermia unit utilizing an array of seven focused ultrasonic transducers," in Proceedings of the IEEE Ultrasonic Symp. (1983), pp. 816-821.

${ }^{4}$ C. J. Diederich, P. R. Stauffer, P. K. Sneed, and T. L. Phillips, “A temperature simulation study of the deep heating capabilities of a rotating multi-transducer ultrasound hyperthermia system," Proceedings of the 6th International Congress on Hyperthermic Oncology (Tucson, Arizona, 1992), Vol. 1, p. 346.

${ }^{5}$ G. K. Svensson, J. L. Hansen, D. D. Carpini, B. Bornstain, and T. Herman, "SAR and temperature distributions from a spherical focused, segmented ultrasound machine," Proceedings of the 6th International Congress on Hyperthermic Oncology (Tucson, Arizona, 1992), Vol. 1, p. 335. ${ }^{6} \mathrm{P}$. P. Lele and K. J. Parker, "Temperature distributions in tissues during local hyperthermia by stationary or steered beams of unfocused or focused ultrasound,"' Br. J. Cancer 45 (suppl v), 108-121 (1982).

${ }^{7}$ P. P. Lele, "Ultrasound: is it the modality of choice for controlled, localized heating of deep tumors?', in Hyperthermia Oncology Vol. 2, edited by J. Overgaard (Taylor and Francis, London, 1984), pp. 129-154.

${ }^{8}$ P. P. Lele, "Advanced ultrasonic techniques for local tumor hyperthermia," in The Radiologic Clinics of North America: Hyperthermia, edited by R. A. Steeves (Saunders, Philadelphia, 1989), Vol. 27, pp. 559-575. ${ }^{9}$ K. Hynynen, R. B. Roemer, D. Anhalt, C. Johnson, Z. X. Xu, W. Swindell, and T. Cetas, "A scanned focused multiple transducer ultrasonic system for localized hyperthermia treatments," Int. J. Hyperthermia 3, 21-35 (1987).

${ }^{10} \mathrm{~J}$. W. Hunt et al., "Design of conical transducers to produce strongly focused ultrasound beams for deep heating,"' Int. J. Hyperthermia 7, 15-28 (1991).

${ }^{11}$ A. W. Dutton, R. B. Roemer, and F. A. Gibbs, "A clinically integrated scanned focused ultrasound hyperthermia," in Proceedings of the 7th International Congress on Hyperthermic Oncology (Rome, Italy, 1996), Vol. 1, p. 92.

${ }^{12}$ C. A. Cain and S. Umemura, "Concentric-ring and sector vortex phased array applicators for ultrasound hyperthermia therapy," IEEE Trans. Microwave Theory Tech. 34, 542-551 (1986).

${ }^{13}$ C. A. Cain, S. Umemura, and M. Ibbini, "Ultrasound phased array hyperthermia applicators," in Proceedings of the 9th IEEE Engineering in Medicine and Biology Society Meeting (1987), p. 640.

${ }^{14}$ R. J. McGough, "An optimal heating strategy for deep hyperthermia with ultrasound phased arrays," in Proceedings of the 7th International Congress on Hyperthermic Oncology (Rome, Italy, 1996), Vol. 2, pp. 564567.

${ }^{15} \mathrm{~K}$. Hynynen, "Biophysics and technology of ultrasound hyperthermia," in Methods of External Hyperthermic Heating, edited by M. Gautherie (Springer, Berlin, 1990), pp. 61-116.

${ }^{16}$ W.-L. Lin, R. B. Roemer, E. G. Moros and K. Hynynen, “'Optimization of temperature distributions in scanned, focused ultrasound hyperthermia,’ Int. J. Hyperthermia 8, 61-78 (1992).

${ }^{17}$ E. G. Moros, R. B. Roemer, and K. Hynynen, "Pre-focal plane high temperature regions induced by scanning focussed ultrasound beams," Int. J. Hyperthermia 6, 351-366 (1990).

${ }^{18} \mathrm{H}$. H. Pennes, "Analysis of tissue and arterial blood temperatures in the resting human forearm," J. Appl. Phys. 1, 93-122 (1948).

${ }^{19} \mathrm{H}$. Arkin, X. Xu, and K. R. Holmes, "Recent developments in modeling heat transfer in blood perfusion tissues," IEEE Trans. Biomed. Eng. 41, 97-107 (1994). 
${ }^{20}$ R. B. Roemer, “Thermal dosimetry," in Thermal Dosimetry Planning, edited by M. Gautherie (Springer, Berlin, 1990), pp. 119-214.

${ }^{21}$ J. C. Chato, "Fundamentals of bioheat transfer," in Thermal Dosimetry and Treatment Planning, edited by M. Gautherie (Springer, Berlin, 1990), pp. $1-56$.

${ }^{22}$ W. L. Nyborg, "Solutions of the bio-heat transfer equation," Phys. Med. Biol. 33, 785-792 (1988)

${ }^{23}$ NCRP Report No. 113, Exposure Criteria for Medical Diagnotics Ultrasound: I. Criteria Based on the Thermal Mechanisms (NCRP, Bethesda, MD, 1992), pp. 52-60.

${ }^{24}$ H. F. Bowman, "Heat transfer mechanism and thermal dosimetry," J. Natl. Cancer Inst., Mon. 61, 437-445 (1981).

${ }^{25}$ J. C. Chato, "Selected thermophysical properties of biological materials," in Heat Transfer in Medicine and Biology, Analysis and Applications, edited by A. Shitzer and R. C. Eberhart (Plenum, New York, 1985), pp. 413-418.
${ }^{26}$ R. G. Gordon, R. B. Roemer, and S. M. Horvath, “A mathematical model of the human temperature regulatory system - transient cold exposure response," IEEE Trans. Biomed. Eng. 23, 434-444 (1976).

${ }^{27}$ R. K. Jain, "Bioheat transfer: Mathematical models of thermal systems," in Hyperthermia Cancer Therapy, edited by F. K. Storm (Hall, Boston, 1983), pp. 9-46.

${ }^{28}$ J. H. Ferziger, Numerical Methods for Engineering Applications (Wiley, New York, 1981).

${ }^{29}$ K. M. Sekins and A. Emery, "Thermal science for physical medicine,'” in Therapeutic Heat and Cold, edited by J. Lehmann (Williams and Wilkins, Baltimore, 1982), pp. 70-132.

${ }^{30}$ H. Reinhold, "Tumor microcirculation," in Proceedings of 1986 NATO advanced study institute on the physics and technology of hyperthermia (Nijhoff, Dordrecht, 1987), pp. 448-457. 